ISSN electrónico: 2172-9077

DOI: https://doi.org/10.14201/fjc2016131131

\title{
INFORMACIÓN TELEVISIVA Y MOVILIDAD. ANÁLISIS DE LAS NOTICIAS MÁS SEGUIDAS A TRAVÉS DE TWITTTER
}

\section{Informative Television and Mobility. News Analysis of the most Followed through Twitter}

\author{
Dra. Leire GÓMEZ RUBIO \\ Profesora ayudante-doctor. Universidad de Valladolid, España \\ E-mail: leire.gomez@hmca.uva.es \\ (iD) http://orcid.org/0000-0002-6436-0297 \\ Dra. Nereida LÓPEZ VIDALES \\ Profesora titular. Universidad de Valladolid, España \\ E-mail: nereida.lopez@hmca.uva.es \\ (iD http://orcid.org/0000-0002-6960-6129
}

Fecha de recepción del artículo: 01/09/2016

Fecha de aceptación definitiva: 08/10/2016

\begin{abstract}
RESUMEN
Redes sociales, como Facebook y Twitter, y aplicaciones móviles, como Periscope, Snatch, WhatsApp, entre otras, son algunas de las vías de comunicación y de acceso a la información en auge en los últimos tiempos, tanto para los usuarios en general, como para los profesionales de la información. Los avances tecnológicos y las innovaciones derivadas fundamentalmente de la web 2.0 han sumado nuevas pantallas a los medios de comunicación tradicionales, de modo que el periódico ya no solo se lee, sino que ahora puede verse y oírse, al tiempo que la televisión, además de verse y oírse, también se lee. A todo ello se suma la movilidad y portabilidad, tan demandada por los usuarios en la actualidad, y en los que la pantalla del móvil tiene un protagonismo e influencia destacada, sobre todo, de la mano de las redes sociales. En esta aportación se describe cuál es la producción y el consumo de noticias de actualidad que se realiza a partir de la información proporcionada por las principales cadenas de televisión generalista en España a través de la red social más móvil, Twitter.
\end{abstract}

Palabras clave: Periodismo móvil; cuarta pantalla; Twitter; redes sociales; televisión generalista.

\begin{abstract}
Social networks such as Facebook and Twitter, and mobile applications such as Periscope, Snapchat, Whatsapp, among others, are some of the emerging ways of communication and access to information in recent times, for both general users and professionals of the information. Technological advances and innovations derived mainly from the web 2.0 have added new screens to traditional media, so that the newspaper can not only be read, but now also can be seen and heard, while television, besides been seen and heard, also read. To this, mobility and portability is added, as demanded by users today, and in which the mobile screen has a prominent role and influence, especially because of social networks. This contribution describes which is the production and consumption of news that comes from the information provided by the principal generalist television channels in Spain through the most mobile social network, Twitter.
\end{abstract}

Key words: Mobile journalism; fourth screen; Twitter; social networks; generalist television. 


\section{INTRODUCCIÓN}

En abril de 2015, Antena 3 se convirtió en el primer canal de televisión que incorporaba la aplicación de Twitter Periscope en sus emisiones, de la mano de la edición de mediodía de sus informativos diarios, Noticias 11. Tan solo unos días después, la Sexta Noticias ofreció, por primera vez, la posibilidad de interactuar con su audiencia a través del teléfono móvil gracias a la puesta en marcha de un servicio con el que los usuarios podían solicitar boletines, vídeos e información de última hora desde las aplicaciones de mensajería instantánea WhatsApp y Telegram². Se trata, sin duda, de dos iniciativas que subrayan el valor del teléfono móvil como medio emisor y receptor de informaciones. Y es que, igual que ya no hace falta comprar un periódico en papel para leer la prensa del día, puesto que podemos hacerlo a través de las múltiples pantallas que nos brinda la triple w, tampoco hace falta conectarse al receptor de radio o al televisor para oír radio o ver televisión.

Las nuevas pantallas derivadas de la implementación de las NTIC e Internet han posibilitado no solo nuevas formas de consumir información, o cualquier otro tipo de contenido sonoro o audiovisual, sino que también han dotado a los pequeños y grandes medios de comunicación de una movilidad y portabilidad hasta hace unos años desconocida. De hecho, si bien en 2006 el primer informe sobre consumo audiovisual a través del móvil en España señalaba las noticias, la música y la información meteorológica como los contenidos audiovisuales que más interesaban a la audiencia, dedicando la mayoría de los encuestados -el 56\%, concretamente- de 1 a 4 horas semanales a la descarga de contenidos audiovisuales (The cocktail analysis, 2008), casi una década después, en 2015, otro informe vuelve a poner de manifiesto la preferencia del móvil como pantalla para el consumo audiovisual. Sin embargo, en esta ocasión, el informe destaca la portabilidad del terminal, ya que el 70\% de los españoles señalan querer, a través de su smartphone, «disfrutar de la libertad de estar conectados en cualquier momento y lugar» (Nielsen, 2015). No en vano, el 100\% de los españoles que se conectan a Internet lo hacen también desde su smartphone y el $90 \%$ de los usuarios se conecta todos o casi todos los días, siendo también el móvil el dispositivo preferido para acceder a las redes sociales e informarse (Ditrendia, 2016). Así, la telefonía móvil ha pasado de ser un medio que ofrecía principalmente servicios de vOz y texto a «convertirse en un medio plenamente audiovisual a través del cual difundir y consumir contenidos de todo tipo: desde clips musicales hasta videojuegos, cortometrajes o contenidos televisivos» (Adelantado y Martí, 2011, p. 101).

Esto ha provocado que del mismo modo que los medios de comunicación tradicionales en su día optaron por sumarse y adecuarse a las posibilidades derivadas de la web, actualmente esos medios estén teniendo que adaptarse a la movilidad ofrecida por la cuarta pantalla. De momento, en el ámbito audiovisual, los vídeos de corta duración son los más consumidos por los usuarios en sus smartphones, mientras que hay otros vídeos «ajenos a su visualización a través del móvil», entre los que se encuentran las noticias deportivas (13\%), los informativos generalistas $(9 \%)$, los eventos deportivos (7\%) o las películas $(6 \%)$. En estos casos, entre el 70 y el $85 \%$ de los usuarios prefiere la televisión para su visualización (Nielsen, 2015).

En lo que al ámbito informativo se refiere, esa portabilidad del teléfono móvil ha traído consigo cambios en los procesos de producción y distribución de las noticias, puesto que «los usuarios de

\footnotetext{
${ }^{1}$ INNOVACIONAUDIOVISUAL.COM (24/04/2015). «Antena 3 Noticias: el primer canal en incorporar Periscope en sus emisiones. Recuperado de https://innovacionaudiovisual.com/2015/04/24/antena-3-noticias-el-primer-canal-en-incorporarperiscope-en-sus-emisiones / (consultado el 17 de agosto de 2016).

2 MOVILONIA.COM (01/05/2015). «La Sexta Noticias, ahora también desde WhatsApp». Recuperado de http://www.movilonia.com/noticias/la-sexta-noticias-en-whatsapp-telegram-twitter-facebook/ (consultado el 4 de julio de 2016).
} 
medios digitales demandan actualización constante y cobertura de hechos noticiosos en tiempo real. Esta situación constituye un desafío donde el periodismo móvil puede erigirse como una respuesta apropiada» (Lovato, 2015, p. 26) que ha encontrado en las redes sociales a «sus aliados privilegiados» a la hora de difundir y compartir información (Moreno, 2015, p. 69). De hecho, según un estudio realizado por Reuters Institute for the Study of Journalism, en 2014, las redes sociales fueron el segundo medio de referencia de los usuarios de Internet menores de 35 años en España, solo por detrás de la televisión convencional. Plataformas como Twitter y Facebook superaron ese año a los diarios impresos como fuente informativa incluso entre los usuarios de la franja de 35 a 44 años. Junto a esto, destaca la idea de que el seguimiento de noticias en televisión generalista entre adultos menores de 25 desciende al 65\%, un porcentaje similar al de jóvenes del mismo grupo de edad que se informan de las noticias a través de las redes sociales $(62 \%)$. Sin embargo, a partir de los 45 años, se sitúa en torno al $80 \%$ (Reuters, 2015). Un año después, ese mismo informe destacaba la preferencia por la información en movilidad, ya que

el $50 \%$ de los usuarios adultos de noticias online menores de 45 años se informa principalmente a través del teléfono móvil, frente al 38\% del ordenador y el 7\% de la tableta, y en general el móvil ya es el dispositivo de referencia informativa de uno de cada tres adultos de cualquier edad (Negredo, Vara-Miguel y Amoedo, 2016. p. 3).

Asimismo, de entre todas las redes sociales existentes, según la encuesta dirigida por Princeton Survey Research Associates Internacional para el último Informe Anual Sobre el Estado de los Medios (2012), los consumidores de noticas a través de Twitter son «más móviles» -un 76\% de estos usuarios tiene un smartphone, frente al 67\%, por ejemplo, de los seguidores de Facebook-, al tiempo que la mayoría de los usuarios de Twitter destaca que «las noticias que consume a través de la red de microblogging no podrían encontrarse en otro sitio $(93 \%) »^{3}$. En esta misma línea, un estudio de Nielsen (2012) señala que «el 80\% de los usuarios españoles accede a Twitter desde el dispositivo móvil, y la mayoría de ellos asegura que el móvil es parte fundamental de la experiencia Twitter».

En consecuencia, hay dos características fundamentales que están marcando hoy la forma de consumir información, fundamentalmente entre los más jóvenes, que son «lo social y lo móvil», a las que se les suman, aunque «en un segundo plano», la rapidez y la superficialidad (Yuste, 2015, p. 180). Pero, ¿qué tipo de información móvil consumen los usuarios a través de las redes sociales? ¿Difiere ese consumo del realizado a través de medios convencionales? Para dar respuesta a ambas preguntas, en las siguientes páginas se muestran los resultados de un estudio ${ }^{4}$ en el que se pone de manifiesto cómo información, televisión, móvil y redes sociales unen su potencial a la hora de ofrecer información de actualidad a sus usuarios. El estudio analiza la información más seguida por los usuarios en Twitter, que es la red social que supera a la suma de todas las demás entre los usuarios más jóvenes a la hora de acceder a noticias $-36 \%$ frente al 33\%- (Reuters, 2015).

\footnotetext{
${ }^{3}$ MARKETINGDIRECTO.COM (20/03/2012). «Cómo influyen Facebook y Twitter en el consumo de información online?». Recuperado de http://www.marketingdirecto.com/digital-general/social-media-marketing/\% $\% 2 \% \mathrm{BFcomo-influyen-facebook-}$ $\mathrm{y}$-twitter-en-el-consumo-de-informacion-online/ (consultado el 7 de julio de 2016).

${ }^{4} \mathrm{El}$ texto aquí presentado proviene de la investigación «Nuevas formas de consumo, creación y producción informativa y otros contenidos audiovisuales» (Cód.: OCENDI07/1618), del Observatorio del Ocio y el Entretenimiento Digital, financiada por Panoramaaudiovisual.com para los años 2016-2018.
} 


\section{OBJETIVOS Y METODOLOGÍA}

El objetivo principal de este trabajo es mostrar qué tipo de noticias son las más seguidas en las páginas oficiales de Twitter de los espacios informativos de las cadenas de televisión generalistas en España, por ser esta red social la que cuenta con un mayor acceso desde dispositivos móviles (Nicolás, 2012, p. 21). De hecho, en 2015, la consulta de Twitter fue el segundo de los servicios más usados por los usuarios de smartphones (86,2\%), tan solo superado por aquellos que emplearon el móvil para la mensajería instantánea $(93,6 \%)$, y por delante de quienes se conectan a redes sociales sin distinciones $(81,2 \%)$ (Fundación Telefónica, 2016). Se trata, en definitiva, de comprobar si el uso que hacen los informativos generalistas de Twitter coincide con los intereses de los usuarios a la hora de consumir información a través de las redes sociales, que es uno de los principales usos que se hacen del móvil.

Junto al objetivo principal, se plantean otros secundarios, entre los que se encuentran:

- Comprobar si los espacios informativos con mayor índice de audiencia convencional son los más seguidos a través de Twitter;

- Analizar si los diferentes programas informativos diarios de las cadenas de televisión generalista cuentan con perfiles de audiencia distintos, teniendo en cuenta las noticias más seguidas a través de las publicadas por dichos espacios en Twitter;

- Conocer si las noticias más seguidas y tuiteadas coinciden con aquellas a las que más tiempo dedican y en mejor posición de la escaleta de emisión colocan los informativos tradicionales de televisión;

- Estudiar si todos los días de la semana cuentan con una actividad similar en esta red social, en lo que a número de tuits publicados y seguidores se refiere.

Para dar respuesta a estos objetivos se ha optado por una metodología fundamentalmente cuantitativa basada en el análisis de contenido. El método de trabajo ha consistido, en primer lugar, en el recuento y análisis de las noticias publicadas por los servicios informativos de los principales canales generalistas de televisión en sus páginas oficiales de Twitter durante una semana continuada de lunes a domingo, en aras a proceder a su clasificación en áreas temáticas y comprobar cuáles son las más seguidas, es decir, las que han sido más retuiteadas entre los seguidores de esa red social. Para ello, se ha elaborado una ficha de recogida de datos con las diez noticias más seguidas en cada uno de los canales objeto de estudio que contiene las siguientes variables de análisis formal y de contenido distribuido:

\begin{tabular}{|l|l|}
\hline - & Canal \\
\hline - & Página oficial de Twitter \\
- & Número de noticias colgadas en Twitter \\
- & Número de veces retuiteada \\
- & Número de veces «me gusta» \\
- & Procedencia de la información \\
- & Temática de la información \\
\hline
\end{tabular}


El periodo de análisis ha sido el comprendido entre los días 25 de abril y 1 de mayo de 2016, y las cadenas analizadas han sido La 1, Telecinco, Antena 3 TV, La Sexta y Cuatro ${ }^{5}$. La elección de la semana a analizar no ha sido casual, sino que ha ido especialmente seleccionada para la investigación al tratarse de una semana con un alto valor informativo en el panorama nacional, puesto que al final de esa semana expiró el plazo para que los partidos políticos con mayoría parlamentaria llegaran a un acuerdo que dotara de Gobierno al Estado y evitara la convocatoria de nuevas elecciones generales.

En lo que a los canales de televisión se refiere, se han elegido los generalistas de ámbito nacional con mayor índice de audiencia, descartando los autonómicos y regionales, para acotar el análisis. Los canales y páginas oficiales de Twitter analizados han sido:

\begin{tabular}{|l|ll|}
\hline Canal & Servicio informativo & Página de Twitter \\
\hline TVE 1 & Telediario & $\underline{\text { https://twitter.com/telediario tve?lang=es }}$ \\
Telecinco & Informativos Telecinco & $\underline{\text { https://twitter.com/informativost5?lang=es }}$ \\
Antena 3 TV & Antena 3 Noticias & $\underline{\text { https://twitter.com/a3noticias?lang=es }}$ \\
La Sexta & La Sexta Noticias & $\underline{\text { https://twitter.com/sextanoticias?lang=es }}$ \\
Cuatro & Noticias Cuatro & $\underline{\text { https://twitter.com/noticias cuatro?lang=es }}$ \\
\hline
\end{tabular}

Respecto a la categorización temática de los tuits, se ha elaborado una clasificación a partir de las empleadas en diversos estudios que contempla las siguientes categorías temáticas: política, economía, sucesos, sociedad, cultura y espectáculos, ciencia y tecnología, salud, educación, tribunales, deportes, varios $^{6}$ y otros.

La hipótesis de partida es que los usuarios de Twitter emplean esta red social para informarse, de manera puntual, de noticias transcendentes y de última hora. Por el contrario, la red es usada de forma habitual para consumir noticias que poco, o nada, tienen que ver con las informaciones de portada de los espacios informativos de televisión, al decantarse, de forma mayoritaria, por noticias que destacan más por lo anecdótico - por el entretenimiento- que por lo informativo.

\section{LA INFORMACIÓN EN TELEVISIÓN}

En abril de 2016, la televisión fue el medio más consumido por la audiencia. Durante ese mes, el consumo de la pequeña pantalla se situó en 236 minutos de promedio diario -tres minutos menos que en abril de 2015-. Por canales, Telecinco repitió como la cadena más vista (15,4\%), seguida por Antena $3(13 \%)$, La $1(10 \%)$, La Sexta $(7,5 \%)$, FORTA $(7,5 \%)$ y Cuatro $(6,7 \%)$.

En lo que a los informativos diarios se refiere, los de Telecinco fueron, durante el periodo analizado, los más vistos en la edición de noche de lunes a domingo, liderato que compartió con el Telediario del primer canal de TVE en la sobremesa de lunes a viernes, mientras que en la sobremesa del fin de semana fue el espacio informativo de La 1 el que encabezó el ranking (Barlovento Comunicación, 2016). Asimismo, cabe destacar que los servicios informativos de Telecinco, Antena 3, La Sexta y La 1 figuran, a lo largo de la semana analizada, y en alguna de sus ediciones, entre los 25 programas más vistos, mientras que Noticias Cuatro solo aparece en la lista el martes 26 de abril7. Asimismo, los infor-

\footnotetext{
${ }^{5}$ El informativo del segundo canal de TVE, La 2, no ha sido incluido en el análisis para este trabajo, debido al bajo nivel de audiencia registrado.

${ }^{6}$ Dentro de esta categoría se incluyen aquellas noticias que, sin encuadrarse en el resto de categorías señaladas, giran en torno a asuntos anecdóticos o de entretenimiento con escaso valor informativo.

${ }^{7}$ Pueden consultarse los datos de audiencia en http://www.formulatv.com/audiencias/ (consultado el 15 de julio de 2016).
} 
mativos diarios de las televisiones generalistas son la fuente preferida para acceder a las noticias (76\%), seguidos por las webs y apps de periódicos (49\%) (Reuters, 2015).

\subsection{LA INFORMACIÓN EN MOVILIDAD A TRAVÉS DE LAS REDES SOCIALES}

Al margen de la pequeña pantalla, los dispositivos digitales, como teléfonos móviles inteligentes (smartphones), tabletas, ordenadores de sobremesa y ordenadores portátiles, entre otros, se han convertido en segundas pantallas donde visualizar el contenido audiovisual (Marta-Lazo y Aguilera, 2015, p. 85), al tiempo que constituyen nuevas vías de acceso a la información de actualidad. A esto hay que sumar la multitud de prestaciones que vienen incorporadas a estos «aparatos» (cámara, juegos, reproductor de música, aplicaciones...), y que en el caso de los teléfonos móviles han contribuido a que su función original, la de hacer llamadas, se haya quedado en una posición secundaria (Yuste, 2015, p. 188).

Tal y como se ha señalado en páginas anteriores, el acceso a redes sociales es una de las principales prestaciones otorgadas por los usuarios a sus teléfonos móviles. No obstante, ¿qué buscan estos usuarios en las redes sociales? Según el último estudio anual de redes sociales (IAB, 2016), el principal uso es el «social», entendiendo por este actividades como «chatear» $(79 \%)$, «ver vídeos, música» (57\%) y «ver qué hacen tus contactos» (48\%), mientras que actividades como «comentar la actualidad» aparece en séptimo lugar, con un $29 \%$, cuando en el informe del año anterior, este uso se situaba en cuarto lugar, con un 34\% (IAB, 2015). Sin embargo, el hecho de que los usuarios no comenten la actualidad a través de las redes sociales no quiere decir que no se sirvan de estas plataformas para informarse. En este sentido, cabe destacar que las redes sociales son la cuarta fuente preferida para informarse (46\%) -y segunda para los usuarios menores de 35 años-, por detrás de los informativos diarios de las televisiones generalistas $(76 \%)$ y a tan solo tres puntos de las webs y apps de periódicos y a uno de los periódicos impresos, mientras que dobla a quienes prefieren los programas informativos de radio (22\%) (Reuters, 2015).

Según el barómetro realizado en abril de 2016 por el Centro de Investigaciones Sociológicas (CIS), el paro, la corrupción y el fraude, los problemas económicos y los políticos, en general, son los principales problemas con los que cuenta España, siendo el paro y los problemas de índole económica los que más le afectan a la ciudadanía (CIS, 2016). Sin embargo, a la hora de consultar las redes sociales para informarse, entre los contenidos compartidos con mayor frecuencia, por ejemplo en Facebook, se encuentran las «ultimas noticias» y los «desastres y muertes», mientras que el resto de categorías de noticias «tienen una presencia mucho menor entre las noticias con mayor número de comentarios (...). Las noticias divertidas y de contenido original obtienen del mismo modo una presencia más alta entre las noticias que no han sido compartidas ninguna vez» (Segado-Boj, Díaz-Campo y Soria, 2015, p. 159).

Aunque por número de usuarios las dos plataformas sociales de mayor repercusión e incidencia son Facebook y Twitter, los principios organizativos de ambas fundamentan una intención comunicativa bien distinta:

En el caso de Facebook se estructura como un entramado social a través del establecimiento de relaciones con otros usuarios que quedan así conectados para intercambiar cualquier información. Sin embargo, y aquí radica una de las diferencias fundamentales con Twitter, inicialmente esta estructura es privada, es decir, requiere de una autorización previa del propietario de la cuenta para la difusión de sus mensajes. En cambio, Twitter se ajusta a una red de contenidos caracterizada por la transmisión viral de la información, inicialmente de acceso público. Por este motivo, 
muchos consideran a Twitter como un nuevo medio de comunicación, cuya importancia radica en la calidad de los seguidores de cada usuario. Además, la posibilidad de reenviar mensajes de otros usuarios fomenta la expansión de la información más relevante en cortos espacios de tiempo $\mathrm{y}$, por supuesto, permite interaccionar con los emisores iniciales (Sequera, 2013).

\subsection{TWITTER Y TELEVISIÓN}

Aunque WhatsApp y YouTube son las redes sociales mejor valoradas, seguidas de Spotify, Instagram, Telegram y Facebook (IAB, 2016), Twitter se ha convertido en lo que algunos han denominado como una «segunda pantalla del televisor», debido «al aumento de actividad que registran los usuarios de Twitter cuando están viendo un programa televisivo, especialmente en horario de máxima audiencia» ${ }^{8}$. Además, Twitter es la red social «que está revolucionando el periodismo actual porque ofrece una inmediatez entre emisor y receptor hasta ahora nunca alcanzada en Internet y que es idónea para seguimientos de congresos, presentaciones mundiales, eventos, encuentros deportivos, etc.» (Caldevilla, 2010, p. 60). Esa inmediatez es, precisamente, una de las características que acentúan la relación entre las redes sociales y el consumo de noticias, «convirtiéndose en un proceso en el que se implican simultáneamente tanto los medios de comunicación como las audiencias» (Segado-Boj, Díaz-Campo y Soria, 2015, p. 154).

Es en las noticias de última hora donde la información mediante las redes sociales, especialmente a través de Twitter debido a la movilidad manifestada por sus usuarios a la hora de acceder a dicha red mediante el teléfono móvil, donde se intensifica su valor como vía de acceso a la información. Los usuarios ya no tienen que esperar a la edición más inmediata del informativo, tanto en radio como en televisión, al igual que tampoco tienen que comprar el periódico o incluso ojear algún medio online a través del propio móvil, para estar al tanto de la actualidad, sino que las últimas horas llegan en primera instancia a través de las redes sociales, haciendo que el hecho noticioso sea antes tuiteado que televisado (Manna, 2015, p. 102). Los atentados de París en noviembre de 2015 o los de Bruselas en marzo de 2016 son dos ejemplos que mostraron el poder de una red social como Twitter como vía de acceso a una información de última hora. Desde el mismo momento en el que se conocía la noticia, los diferentes medios de comunicación, tanto nacionales como extranjeros, comenzaron a dar cuenta de lo ocurrido en Twitter a través de mensajes de texto y audiovisuales que, a su vez, los usuarios de la red compartieron entre sus comunidades de amigos.

Sin embargo, al margen de las noticias de última hora, actualmente,

incluso entre los internautas, las marcas televisivas de noticias siguen obteniendo casi dos terceras partes de su audiencia informativa exclusivamente a través de la emisión tradicional, y solo una cuarta parte son usuarios duales, es decir, consumen noticias con ellas tanto offline como online (Negredo, Vara Miguel y Amoedo, 2016, p. 12).

Esto hace que en el caso de las televisiones de ámbito estatal generalista en España (Antena 3, La Sexta, TVE 1, Telecinco y Cuatro), los usuarios que se informan con ellas «solo online, por sus webs y aplicaciones, supongan una de cada diez personas a las que llegan de forma combinada». Antena 3, La Sexta y RTVE son los tres canales de televisión que cuentan con mayor audiencia dual, entre un 18 y

${ }^{8}$ LIBERTADDIGITAL.COM (09/07/2014). «El 66 por ciento de los usuarios de móvil tuitea mientras ve la televisón». Recuperado de http://www.libertaddigital.com/ciencia-tecnologia/internet/2014-07-09/el-66-por-ciento-de-usuarios-de-moviltuitean-mientras-ve-la-television-1276523404/ (consultado el 25 de junio de 2016). 
un 11\%, mientras que Telecinco y Cuatro oscilan entre el 8 y el 10\%, respectivamente (Negredo, Vara Miguel y Amoedo, 2016, p. 12).

Junto a esto, también cabe destacar que «Twitter ha cambiado el modo en el que vemos la televisión», debido a que muchos programas suscitan un mayor interés por «su debate en directo a través de la red social que por su calidad intrínseca televisiva». Esto provoca que, en ocasiones,

hay quien va de Twitter a la televisión porque ha sido avisado de un contenido interesante a través de un contacto, pero también quien se mueve de la televisión a Twitter, buscando en esta plataforma más argumentos para seguir consumiendo el producto que le está ofreciendo la gran pantalla (Noguera, 2012, p. 56-57).

\section{CONSUMO DE LAS NOTICIAS DE LOS INFORMATIVOS GENERALISTAS EN TWITTER}

Según datos proporcionados por Kantar Media, durante el mes de abril de 2016 se registraron más de 4,3 millones de tuits sobre programas de televisión, siendo Telecinco el canal que acumuló el mayor número de tuits, seguido por La Sexta, Antena 3, La 1, 13 TV, Cuatro, Mega y TV3. En este sentido, las emisiones de televisión con mayor presencia en la red social fueron GH Vip (Telecinco), Salvados (La Sexta), Sálvame Naranja (Telecinco), y El Príncipe (Telecinco) (Barlovento Comunicación, 2016). En lo que a espacios informativos se refiere, y según la investigación aquí realizada, Antena 3 Noticias y La Sexta Noticias son los dos programas que cuentan con el mayor número de tuits en sus páginas oficiales durante la semana de análisis. Juntos acumulan más de la mitad de los mensajes volcados en las cuentas de Twitter de los principales espacios informativos de carácter generalista y ámbito estatal. Les siguen Informativos Telecinco, que acumula el 16\% de los tuits registrados en esos días, el Telediario del primer canal de TVE y Noticias Cuatro, con el 15\% y 14\%, respectivamente.

\section{Gráfico 1. Número de tuits registrados en los informativos}

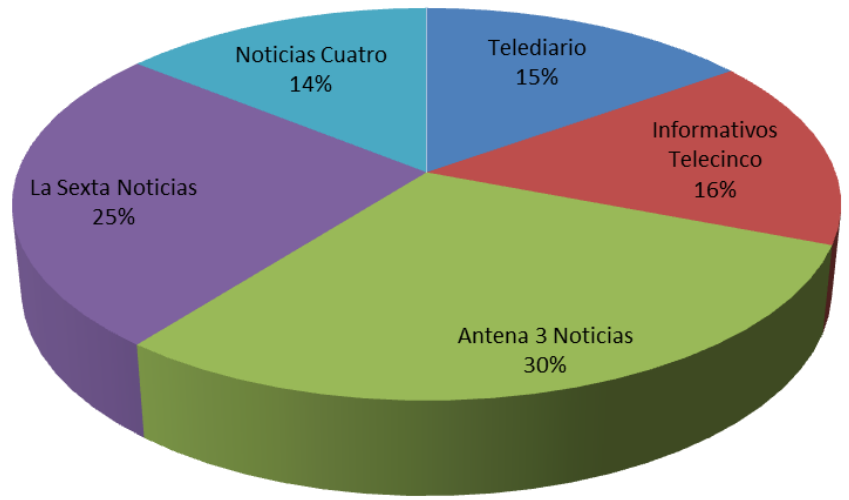

Fuente: elaboración propia. 
Tenemos, por tanto, que mientras los dos canales generalistas de Atresmedia son los favoritos por los usuarios de Twitter a la hora de consumir información a través de esta red social, Telecinco, de Mediaset, fue el canal que en abril lideró el ranking de audiencia social. Aun así, hay que destacar que ningún programa informativo diario figura entre los espacios televisivos más seguidos a través de Twitter.

Por canales, Antena 3 Noticias, con 813 tuits en total, ronda e incluso supera los 100 tuits diarios la mayor parte de los días analizados, algo que también ocurre, aunque en menor medida, con La Sexta Noticias, cuyos tuits ascienden a 688. El número de informaciones publicadas en la red social por los diferentes informativos varía dependiendo del día de la semana y del canal. Así, viernes, sábado y domingo fueron los días con mayor número de tuits en TVE, oscilando entre los 64 y los 67; para Informativos Telecinco, el martes y el jueves fueron las jornadas con mayor actividad en la red social, en torno a las 70 informaciones diarias; en Antena 3 Noticias, el lunes, martes y viernes, superando los 120 apuntes informativos; en La Sexta Noticias, el domingo, con 120 tuits, y en Noticias Cuatro, el martes, con 71 informaciones.

Gráfico 2. Número de informaciones publicadas en Twitter de lunes a domingo

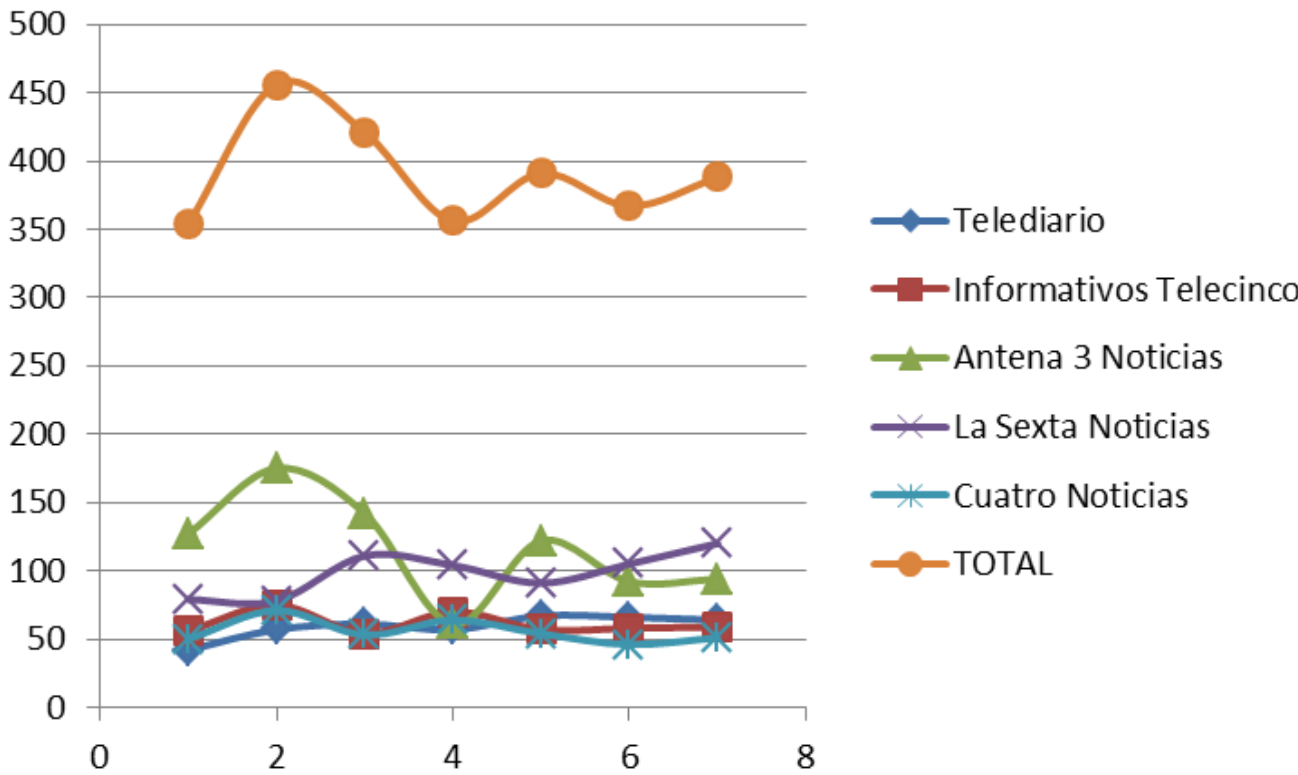

Fuente: elaboración propia.

\subsection{NATURALEZA DE LAS INFORMACIONES MÁS SEGUIDAS A TRAVÉS DE TWITTER}

Dentro de las informaciones más seguidas en Twitter durante la semana objeto de análisis, pocas tienen que ver con el tema informativo de esos días, que es la fecha límite para llegar a un acuerdo entre los partidos políticos que permita formar Gobierno o el anuncio de nuevas elecciones. De hecho, de corte político solo nos encontramos con dos informaciones entre las diez más tuiteadas: la primera de ellas es la que hace referencia a la denuncia de afiliados y exmilitantes de Ciudadanos ${ }^{9}$ al

\footnotetext{
${ }^{9}$ Partido político español fundado en Barcelona en 2006 y presidido por Albert Rivera. 
partido por financiación ilegal, retuiteada 363 veces en La Sexta Noticias, mientras que la segunda es la calificación de «circo» por parte del diario New York Times a la situación política española, con 353 tuits en Antena 3 Noticias. Asimismo, cabe destacar que ambas informaciones ocupan los dos últimos puestos dentro de los diez apuntes informativos más seguidos. Este ranking está encabezado por informaciones, tanto nacionales como internacionales, generalmente de carácter social que, salvo excepciones, como es el caso de la información más tuiteada referente a la detención del director porno Torbe por grabar con menores y por agresiones sexuales, están más cerca del ámbito anecdótico que del informativo. Así, entre las noticias que superan los 500 tuiteos nos encontramos las relacionadas con la muerte de un elefante en Camboya por llevar turistas a altas temperaturas o el rescate de la policía inglesa de dos gatos cubiertos de tinta.

Tabla 1. Ranking de las diez informaciones más tuiteadas en los informativos diarios

\begin{tabular}{|l|l|l|l|}
\hline Día & Canal & \multicolumn{1}{|c|}{ Información } & N. $^{\mathbf{} \text { tuiteos }}$ \\
\hline 26 abril & Antena 3 & $\begin{array}{l}\text { «Detenido el director porno Torbe por grabar con menores y por } \\
\text { agresiones sexuales» }\end{array}$ & 757 \\
\hline 25 abril & Antena 3 & «Muere un elefante por llevar turistas a 40 grados en Camboya» & 532 \\
\hline 26 abril & Antena 3 & $\begin{array}{l}\text { «La policía inglesa rescata a Pitufo y Shrek, dos gatos cubiertos de tinta } \\
\text { permanente» }\end{array}$ & 509 \\
\hline 27 abril & La Sexta & «Ignacio Escolar: me despiden por lo mismo que...» & 508 \\
\hline 1 mayo & Antena 3 & $\begin{array}{l}\text { «La India pinta pasos de cebra en 3D para conseguir que los coches } \\
\text { frenen ante ellos» }\end{array}$ & 409 \\
\hline 25 abril & Antena 3 & $\begin{array}{l}\text { «El guardia civil que ha matado a un conductor en la A3 da positivo en } \\
\text { Cannabis» }\end{array}$ & 409 \\
\hline 1 mayo & TVE & «Carolina Marín, campeona de Europa por segunda vez» & 396 \\
\hline 26 abril & Antena 3 & $\begin{array}{l}\text { «Una pareja de buitres gay incuba un huevo rechazado por una hembra } \\
\text { en un zoo de Alemania» }\end{array}$ & 369 \\
\hline 25 abril & La Sexta & $\begin{array}{l}\text { «Afiliados y exmilitantes de Ciudadanos denuncian al partido por } \\
\text { financiación ilegal» }\end{array}$ & 363 \\
\hline 27 abril & Antena 3 & «El New York Times califica de circo la situación política española» & 353 \\
\hline
\end{tabular}

Fuente: elaboración propia.

De este modo, aunque las informaciones relacionadas con sucesos, política y sociedad aglutinan la mitad de las informaciones publicadas por los servicios informativos en la red social, son las incluidas dentro de la categoría de «varios» y de «sociedad», sobre todo, las más seguidas y retuiteadas por los usuarios de Twitter. En consecuencia, nos encontramos con que las informaciones más seguidas en esta plataforma social guardan cierta similitud con el tipo de programas más comentados en las redes sociales, que son de entretenimiento, los espacios deportivos y la ficción-que aglutinan entre el 17 y el 15\% de los comentarios cada uno- (Gómez, Paniagua y Farias, 2014). 
Gráfico 3. Naturaleza de las informaciones publicadas en Twitter

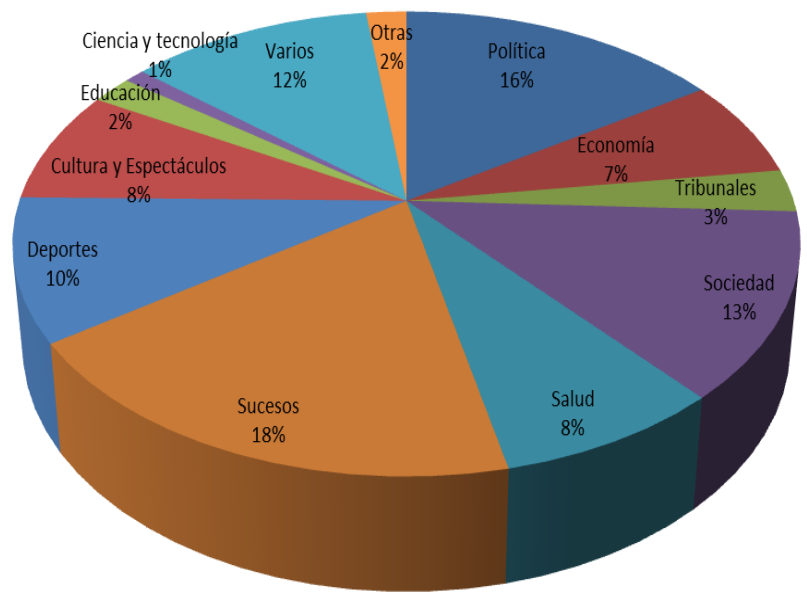

Fuente: elaboración propia.

En lo que al origen de las noticias publicadas se refiere, los informativos se decantan de forma mayoritaria por aquellas de ámbito nacional.

Gráfico 4. Origen de las informaciones publicadas en Twitter

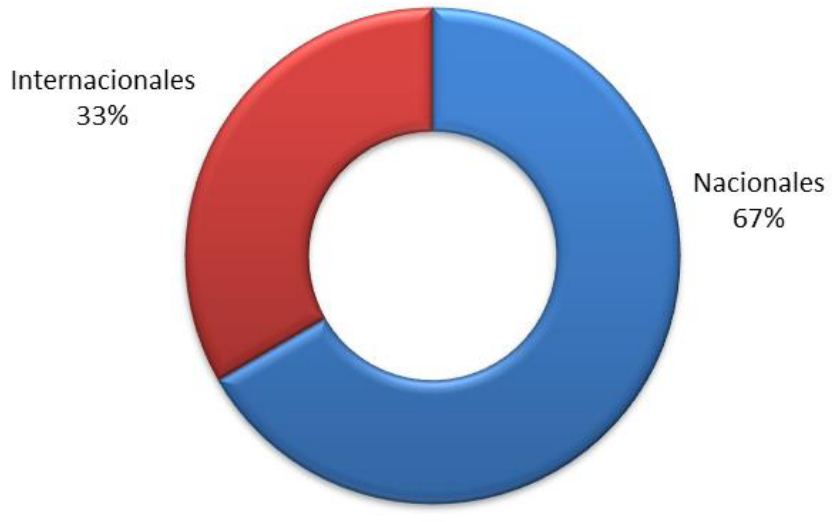

Fuente: elaboración propia. 


\subsection{UN INFORMATIVO ¿UN PERFIL DE AUDIENCIA DIFERENTE? ANÁLISIS DE LAS INFORMACIONES MÁS TUITEADAS POR LOS INFORMATIVOS GENERALISTAS}

Como canales de televisión generalistas, los informativos diarios de las cadenas aquí analizadas Telecinco, Cuatro, Antena 3, La Sexta y La 1- pretenden llegar al mayor número de audiencia, sin distinciones por edad o género, entre otras variables. Esto hace que, si echamos un vistazo al contenido de sus informativos, nos encontremos con que prácticamente todos incluyen las mismas noticias, siendo el orden otorgado en la escaleta de emisión, el enfoque y el formato elegido para contar la información las principales diferencias entre estos programas.

En la semana objeto de análisis, todos los informativos estudiados abordaron durante sus primeros minutos de emisión alguna información relativa a la situación política del país. Tal y como se detalla en la tabla 2, el tiempo dedicado por los informativos a los titulares estuvieron copados por los contactos del Rey con las diferentes fuerzas políticas, el inicio de la precampaña electoral, la presencia de Arnaldo Otegi en el Parlamento Europeo, los bombardeos del Estado Islámico en Alepo, la reapertura de la terminal de salidas de Bruselas tras los atentados, el 30 aniversario del accidente de Chernóbil, la salida de Irene Lozano y Carme Chacón de las listas del PSOE, la llegada del puente de mayo o el crecimiento de la economía.

Tabla 2. Primeras noticias emitidas por los informativos diarios de las cadenas generalistas

\begin{tabular}{|c|c|}
\hline Día & Noticia \\
\hline Lunes & $\begin{array}{l}\text { Ronda de terceras consultas del Rey } \\
\text { El Rey pide a los políticos que se reduzcan los costes de la campaña electoral } \\
\text { Reunión a } 5 \text { en Bruselas para combatir el Daesh } \\
\text { Reapertura de la terminal de Bruselas } 40 \text { días después de los atentados } \\
30 \text { años del accidente de Chernóbil } \\
\text { Detenido un guardia civil acusado de matar a un conductor } \\
\text { Obama regresa a EE. UU. tras su gira europea } \\
\text { Madrid, Barcelona y Palma de Mallorca son quienes más multan a los conductores } \\
\text { Rafa Nadal se querella contra la ministra francesa que le acusó de dopaje }\end{array}$ \\
\hline Martes & $\begin{array}{l}\text { El Rey no propone candidato; anuncio de nuevas elecciones } \\
\text { Imágenes del terrorista del } 13 \text { de noviembre en París } \\
\text { Arnaldo Otegi acude al Parlamento Europeo; no se disculpa por los atentados de ETA; califica de presos } \\
\text { políticos a los etarras rencarcelados y de refugiados a los huidos } \\
\text { El Supremo abre una causa a la diputada de Podemos, Victoria Rosell, por cohecho y prevaricación } \\
\text { Accidente mortal en Lorca } \\
30 \text { años de Chernóbil } \\
\text { Rafa Nadal presenta querella por difamación contra una ministra francesa }\end{array}$ \\
\hline Miércoles & $\begin{array}{l}\text { Inicio de la precampaña } \\
\text { Acuerdo entre el Gobierno y la Generalitat } \\
\text { Una pareja detenida por la muerte del hijo de ella } \\
\text { Victoria Rosell deja su puesto en la Diputación } \\
\text { Ingreso en la cárcel de Salah Abdesalam por los atentados de París } \\
\text { Donald Trump a punto de convertirse en el candidato republicano único } \\
\text { Funcionarios de Venezuela solo trabajarán lunes y martes para ahorrar energía } \\
\text { La DGT pone } 34.000 \text { multas en una semana por exceso de velocidad } \\
\text { España, segundo país más ruidoso después de Japón según la OMS } \\
\text { Prueban en las minas de Riotinto un equipo para Marte } \\
\text { Rafa Nadal será en abanderado de España en Brasil } \\
\text { El Rey Felipe VI y la infanta Leonor acuden al Calderón }\end{array}$ \\
\hline Jueves & $\begin{array}{l}\text { Irene Lozano y Carme Chacón no repetirán en las listas del PSOE } \\
\text { Último pleno de la legislatura (con bronca, desalojo) }\end{array}$ \\
\hline
\end{tabular}




\begin{tabular}{|c|c|}
\hline \multirow[b]{2}{*}{ Viernes } & $\begin{array}{l}\text { Sáenz de Santamaría recibe a Oriol Junqueras en La Moncloa } \\
\text { Aumenta en paro en el primer trimestre del año } \\
\text { Numerosos heridos durante la manifestación de estudiantes y sindicalistas en París por la reforma laboral } \\
\text { Bombardeo en un hospital de Alepo } \\
\text { Nuevas medidas de tráfico para evitar accidentes } \\
43 \text { años de «Eres tú» de Mocedades en Eurovisión } \\
\text { Victoria del Atlético de Madrid en la Champions }\end{array}$ \\
\hline & $\begin{array}{l}\text { Crece la economía española } \\
\text { Llega el puente de mayo } \\
\text { Podemos propone límites a la propiedad de medios de comunicación } \\
\text { Batet, candidata al PSC } \\
\text { Caso Ausbanc } \\
\text { Eurovisión retira la Ikurriña de la lista de banderas prohibidas } \\
\text { Alepo, bombardeada sin descanso } \\
\text { La DGT pone en marcha un dispositivo especial para el puente } \\
\text { Lucha por el liderato de la Champions }\end{array}$ \\
\hline \multirow[b]{2}{*}{ Domingo } & $\begin{array}{l}\text { Pedro Sánchez repetirá su candidatura a la presidencia del Gobierno } \\
\text { Crece la tensión en Irak } \\
\text { Llegan a Lampedusa los superviviente del último naufragio } \\
\text { Fallece un soldado de la UME } \\
\text { Regresan los militares y bomberos del terremoto de Ecuador } \\
\text { Quema de colmillos de elefantes en Nairobi } \\
\text { Don Juan Carlos y Doña Sofía, en Suecia } \\
\text { Alepo, } 9 \text { días bombardeada } \\
\text { Agresión brutal de una madre a su hija } \\
\text { Celebración en Navarra del día de la Almadía }\end{array}$ \\
\hline & $\begin{array}{l}\text { Día Internacional del Trabajo } \\
\text { Reabren parcialmente la terminal de salidas del aeropuerto de Bruselas } \\
\text { Bombardeos Alepo } \\
\text { Las encuestas sobre estimación de voto dan la victoria al PP } \\
\text { Dos corredores fallecen en carreras populares } \\
\text { Despedida al soldado de la UME } \\
\text { Leones rescatados de circos vivirán en libertad } \\
\text { EE. UU., Obama se ha despedido en la tradicional cena de corresponsales } \\
\text { Carolina Marín gana la final de Europa }\end{array}$ \\
\hline
\end{tabular}

Fuente: elaboración propia.

Como puede verse, se trata, en su mayoría, de noticias sobre política de ámbito nacional, que alternan su presencia en los titulares de los informativos de televisión con sucesos y con asuntos internacionales relacionados con, sobre todo, con los bombardeos en Siria. Son, por tanto, informaciones que ocupan los primeros minutos de los noticieros televisivos atendiendo al criterio de actualidad y trascendencia de los hechos.

Sin embargo, cuando se trata de publicar hechos noticiosos en Twitter, los canales de televisión no siempre coinciden en las noticias seleccionadas. $\mathrm{Y}$ es que al igual que la finalidad y la motivación de los internautas cuando hacen uso de una o varias redes sociales no siempre es la misma (GómezRubio y López-Vidales, 2015, p. 140), las cadenas de televisión también encuentran en las redes la posibilidad de diferenciarse del resto mediante la difusión, por ejemplo, de noticas que no tienen cabida en las emisiones convencionales de sus canales, así como de aquellas que saben que no van a ser ofrecidas por otros canales.

\subsubsection{LA SEXTA Noticias}


Más de la mitad de las diez noticias más seguidas en Twitter de las publicadas por La Sexta Noticias -concretamente seis- se engloban bajo la temática «varios». Todas ellas, además, están relacionadas con el mismo tema: el despido por parte de Prisa del periodista Ignacio Escolar, siendo este el gran tema de la semana en la red social. Esta información es la que encabeza el ranking de noticias más retuiteadas en la red del espacio informativo de la cadena, superando los 500 tuiteos. El resto de informaciones más seguidas se reparten entre aquellas relacionadas con asuntos de política, deporte y educación, todas ellas dentro del ámbito nacional, a las que se suma, dentro de las informaciones más seguidas, una de ámbito internacional, correspondiente al fallecimiento del último pediatra que quedaba en Alepo (Siria). Junto a ello, destaca también que el miércoles es el día que concentra los seis apuntes informativos más seguidos, mientras que el martes, el sábado y el domingo no cuentan con ninguna de las informaciones más consultadas por los usuarios de esta red social.

Por lo tanto, la audiencia social de La Sexta Noticias se decanta, durante la semana analizada, por informaciones centradas en temas nacionales - tan solo una de las noticias más seguidas es de ámbito internacional-, destacando especialmente aquellos asuntos que giran en torno a nombres propios, como es el caso del relacionado con el periodista Ignacio Escolar, que prima frente a otros temas que afectan a la ciudadanía en general, como los referidos al libro de texto que culpa a las mujeres y a los inmigrantes del desempleo.

Tabla 3. Informaciones más tuiteadas en La Sexta Noticias

\begin{tabular}{|c|c|c|c|}
\hline Día & Información & N. ${ }^{\circ}$ de tuiteos & Temática \\
\hline Miércoles & «Ignacio Escolar: me despiden por lo mismo que...» & 508 & Varios \\
\hline Lunes & $\begin{array}{l}\text { «Afiliados y exmilitantes de Ciudadanos denuncian al } \\
\text { partido por financiación ilegal» }\end{array}$ & 363 & Política \\
\hline Viernes & «Muere el último pediatra de Alepo» & 213 & Salud \\
\hline Miércoles & «Ignacio Escolar: me despiden por lo mismo que...» & 191 & Varios \\
\hline Miércoles & $\begin{array}{l}\text { «Prisa prohíbe a sus periodistas venir a La Sexta como } \\
\text { colaboradores» }\end{array}$ & 160 & Varios \\
\hline Miércoles & «Apoyo de J. Évole a I. Escolar» & 158 & Varios \\
\hline Jueves & $\begin{array}{l}\text { «El Toledo B-Marchemalo, investigado por la Liga } \\
\text { por supuesto amaño» }\end{array}$ & 157 & Deportes \\
\hline Miércoles & $\begin{array}{l}\text { «Cebrián traiciona a la hemeroteca con su despido a I. } \\
\text { Escolan». «Hay que publicar sin importar las presio- } \\
\text { nes» }\end{array}$ & 154 & Varios \\
\hline Viernes & $\begin{array}{l}\text { «Un libro de texto de Bachillerato culpa del paro a las } \\
\text { mujeres y a los inmigrantes» }\end{array}$ & 153 & Educación \\
\hline Miércoles & «Despido I. Escolar» & 146 & Varios \\
\hline
\end{tabular}

Fuente: elaboración propia.

\subsubsection{TELEDIARIO}

En el caso del informativo del primer canal de la televisión pública, más de la mitad de las informaciones más seguidas se reparten a partes iguales entre aquellas vinculadas al deporte y a la política. En el primero de los casos, las noticias están relacionadas, por un lado, con el triunfo de Carolina Marín en el campeonato europeo de bádminton, y, por otro lado, con la elección de Rafa Nadal como abanderado de España en los Juegos Olímpicos de Brasil. Se trata, por lo tanto, de informaciones que hacen referencia a la proyección que, a nivel internacional, tienen deportistas españoles. En el caso de 
las noticias políticas, nos encontramos con una nacional, que hace referencia al homenaje del Gobierno a un soldado de la Unidad Militar de Emergencias (UME) fallecido; las otras dos informaciones corresponden al mismo hecho, que es la posibilidad con la que cuenta Austria de restringir el derecho de asilo gracias a la aprobación de una ley. Este apunte informativo aparece dos veces dentro de las diez noticias más seguidas en Twitter en este noticiero: la primera vez es retuiteado 67 veces y la segunda, 53. El resto de noticias hacen referencia a dos sucesos, varios y otros. En este último caso, destaca el hecho de que se trata de un tuit promocional de la propia cadena, ya que da a conocer una iniciativa contra el cáncer.

Por días de la semana, el miércoles es el que reúne el mayor número de noticias, seguido por el domingo, mientras que los jueves y los sábados no cuentan en su haber con ninguna de las diez noticias más seguidas en el Twitter del informativo.

Así, en el caso del Telediario, los usuarios de Twitter se decantan por aquellas informaciones con las que el canal busca, también a través de esta red social, proyectar una imagen positiva de España, como son las deportivas, eludiendo la falta de acuerdo entre las principales fuerzas políticas del país cuya consecuencia será la convocatoria de nuevas elecciones generales.

Tabla 4. Informaciones más tuiteadas en el Telediario

\begin{tabular}{|c|c|c|c|}
\hline Día & Información & N. ${ }^{\circ}$ de tuiteos & Temática \\
\hline Domingo & $\begin{array}{l}\text { «Carolina Marín, campeona de Europa por segunda } \\
\text { vez» }\end{array}$ & 396 & Deportes \\
\hline Domingo & $\begin{array}{l}\text { «Defensa impone la medalla al mérito militar y la de } \\
\text { protección civil póstuma al soldado de @UME gol } \\
\text { que murió» }\end{array}$ & 114 & Política \\
\hline Martes & $\begin{array}{l}\text { «Tal día como hoy de } 1986 \text { tuvo lugar el mayor } \\
\text { accidente nuclear de la historia» }\end{array}$ & 95 & Sucesos \\
\hline Miércoles & $\begin{array}{l}\text { «Rafael Nadal elegido para abanderar a España en } \\
\text { los JJOO de Río 2016» }\end{array}$ & 67 & Deportes \\
\hline Miércoles & $\begin{array}{l}\text { «Austria aprueba la ley que permite declarar un } \\
\text { Estado de emergencia migratorio y restringir el } \\
\text { derecho de asilo» }\end{array}$ & 67 & Política \\
\hline Miércoles & $\begin{array}{l}\text { «Detenido el soldado sospechoso de asesinar a once } \\
\text { personas, entre ellas dos españoles, en Cabo Verde» }\end{array}$ & 58 & Sucesos \\
\hline Miércoles & $\begin{array}{l}\text { «Última hora. Austria aprueba la ley que permite } \\
\text { declarar estado de emergencia migratorio y reducir } \\
\text { el derecho de asilo» }\end{array}$ & 53 & Política \\
\hline Domingo & «Revive el oro de Carolina Marín» & 35 & Deportes \\
\hline Lunes & $\begin{array}{l}\text { «Luis Noel, un niño autista al que emociona Fix } \\
\text { You de Coldplay» }\end{array}$ & 28 & Varios \\
\hline Viernes & $\begin{array}{l}\text { «En RTVE apoyamos la lucha contra el cáncer y } \\
\text { promovemos la ayuda a la investigación (RTVE } \\
\text { lanza la segunda edición de Conciencia contra el } \\
\text { cáncer)» }\end{array}$ & 26 & Otros \\
\hline
\end{tabular}

Fuente: elaboración propia.

\subsubsection{INFORMATIVOS TELECINCO}


En Informativos Telecinco, entre las diez noticias más seguidas en Twitter, nos encontramos con dos informaciones políticas, dos de cultura y espectáculos, otras dos sobre sucesos, y el resto, con un apunte informativo cada una, corresponde a varios, sociedad, deportes y economía. En el caso de las noticias políticas, ninguna de las dos habla de la falta de acuerdo entre los principales partidos políticos en España, sino que una de ellas alude a la opinión del candidato a la presidencia por Ciudadanos sobre el Acuerdo del Pardo, y la otra, a la abstención de Podemos en el Congreso en una iniciativa que afecta a los presos políticos. Las demás noticias, a excepción de las que hacen referencia a sucesos, siguen la misma línea que las de política, ya que giran sobre temas con escasas posibilidades de ocupar varios minutos en los informativos diarios de cualquier canal de televisión generalista. Algunas de esas noticias más seguidas en la red social son la fiesta de cumpleaños del fundador de Inditex, la próxima visita a España de Selena Gómez o el apoyo de la Unión de Actores a Alberto San Juan. La única noticia que cuenta con un interés público es la que hace referencia a si la Banca tendrá que devolver todas las cláusulas suelo de las hipotecas.

El lunes es el día de la semana que cuenta con el mayor número de noticias más tuiteadas, mientras que el jueves es el único día que no registra ninguna de las diez informaciones más seguidas en Twitter.

Tabla 5. Informaciones más tuiteadas en Informativos Telecinco

\begin{tabular}{|l|l|c|c}
\hline \multicolumn{1}{|c|}{ Día } & \multicolumn{1}{|c|}{ Información } & N. ${ }^{0}$ de tuiteos & Temática \\
\hline Martes & «Esto opina Albert Rivera del Acuerdo del Pardo» & 145 & Política \\
\hline Sábado & $\begin{array}{l}\text { «La Unión de actores muestra su apoyo a Alberto } \\
\text { San Juan tras la denuncia de la AVT» }\end{array}$ & 78 & Varios \\
\hline Lunes & «En noviembre viene a Madrid ...@selenagomez» & 67 & Cultura \\
\hline Viernes & $\begin{array}{l}\text { «Las lágrimas de Amancio Ortega en su fiesta de } \\
\text { cumpleaños» }\end{array}$ & 49 & Sociedad \\
\hline Miércoles & $\begin{array}{l}\text { «Podemos se abstiene en la iniciativa del Congreso } \\
\text { para liberar a los presos políticos» }\end{array}$ & 48 & Política \\
\hline Lunes & $\begin{array}{l}\text { «Un guardia civil mata de un disparo a un conduc- } \\
\text { tor» }\end{array}$ & 36 & Sucesos \\
\hline Lunes & $\begin{array}{l}\text { «Es una vergüenza que me hayan dejado así la boca } \\
\text { y no se haya pitado ni falta» }\end{array}$ & 33 & Deportes \\
\hline «La Banca tiembla: ¿tendrá que devolver todas las \\
cláusulas suelo de las hipotecas?»
\end{tabular}

Fuente: elaboración propia.

\subsubsection{ANTENA 3 Noticias}

En Antena 3 Noticias, dentro de las informaciones más retuiteadas destacan las incluidas dentro de la temática «varios», que engloba noticias más relacionadas con la anécdota que con asuntos de actualidad informativa. Así, dentro de estas encontramos, por ejemplo, el rescate de la policía inglesa de dos gatos cubiertos de tinta permanente, la muerte de un elefante en Camboya por llevar turistas a altas temperaturas o pasos de cebra pintados en 3D en La India. La audiencia social de este informativo también muestra su preferencia por la detención del director de cine porno Torbe, que figura entre las 
noticias más seguidas con dos informaciones; el positivo en cannabis del guardia civil que ha matado a un conductor en la A3, y la información del New York Times, que tilda de «circo» la situación política española.

Por días de la semana, a excepción del viernes y sábado, todos los demás días cuentan con algún apunte informativo que se sitúa entre las noticias más seguidas en el Twitter del informativo. El día que más noticias aporta al ranking de las más retuiteadas es el martes, con cuatro informaciones, seguido de lunes y miércoles, con dos noticias cada uno.

Por consiguiente, en el caso de Antena 3 Noticias, los seguidores del espacio informativo en Twitter se decantan, sobre todo, por noticias poco relacionadas con el panorama informativo del momento, eligiendo y retuiteando, especialmente, informaciones «curiosas», que quedan lejos de ocupar los primeros minutos de la escaleta informativa en televisión.

Tabla 6. Informaciones más tuiteadas en Antena 3 Noticias

\begin{tabular}{|c|c|c|c|}
\hline Día & Información & $\mathbf{N}^{\circ}{ }^{\circ}$ de tuiteos & Temática \\
\hline Martes & $\begin{array}{l}\text { «Detenido el director porno Torbe por grabar con } \\
\text { menores y por agresiones sexuales» }\end{array}$ & 757 & Tribunales \\
\hline Lunes & $\begin{array}{l}\text { «Muere un elefante por llevar turistas con temperaturas } \\
\text { de } 40 \text { grados en Camboya» }\end{array}$ & 532 & Varios \\
\hline Martes & $\begin{array}{l}\text { «La policía inglesa rescata a Pitufo y Shrek, dos gatos } \\
\text { cubiertos de tinta permanente» }\end{array}$ & 509 & Varios \\
\hline Domingo & $\begin{array}{l}\text { «La India pinta pasos de cebra en } 3 \mathrm{D} \text { para conseguir } \\
\text { que los coches frenen ante ellos» }\end{array}$ & 409 & Varios \\
\hline Lunes & $\begin{array}{l}\text { «El guardia civil que ha matado a un conductor en la A3 } \\
\text { da positivo en cannabis» }\end{array}$ & 409 & Sucesos \\
\hline Martes & $\begin{array}{l}\text { «Una pareja de buitres gay incuba un huevo rechazado } \\
\text { por una hembra en un zoo alemán» }\end{array}$ & 368 & Varios \\
\hline Miércoles & $\begin{array}{l}\text { «El New York Times califica de circo la situación políti- } \\
\text { ca española» }\end{array}$ & 353 & Política \\
\hline Jueves & $\begin{array}{l}\text { «Prisión sin fianza para el director de cine Torbe por } \\
\text { trata de seres humanos» }\end{array}$ & 341 & Tribunales \\
\hline Martes & $\begin{array}{l}\text { «Una limpiadora aficionada a las series policiacas que } \\
\text { ayudó a resolver un crimen en Sevilla» }\end{array}$ & 333 & Varios \\
\hline Miércoles & $\begin{array}{l}\text { «eones maltratados en circos volverán a disfrutar de la } \\
\text { libertad en Sudáfrica» }\end{array}$ & 287 & Varios \\
\hline
\end{tabular}

Fuente: elaboración propia.

\subsubsection{Noticias CuATro}

En Noticias Cuatro, las noticias sobre política son las que más figuran entre las más seguidas en Twitter, pero ninguna de ellas está relacionada con la noticia política más destacada durante la semana de análisis: una, hace referencia a la abstención de Podemos a una iniciática para liberar a presos políticos en Venezuela; otra, a la presencia de Otegi en el Parlamento Europeo; y una tercera, a la conmemoración de 42 aniversario de la Revolución de los Claveles. Las temáticas de deportes, economía y cultura y espectáculos están presentes con una noticia cada uno, mientras que sucesos y varios cuentan con dos noticias cada una. 
En el caso de este informativo, el lunes es el día que cuenta con un mayor número de noticias entre las más seguidas, con un total de cinco, mientras que el fin de semana no registra ninguna; martes, miércoles y jueves solo cuentan con una cada día, y el viernes tiene dos.

De este modo, la audiencia social de Noticias Cuatro se decanta más por noticias políticas, que, sin embargo, tampoco en este caso están relacionadas con la noticia más destacada de la semana.

Tabla 7. Informaciones más tuiteadas en Noticias Cuatro

\begin{tabular}{|c|c|c|c|}
\hline Día & Información & N. ${ }^{\circ}$ de tuiteos & Temática \\
\hline Miércoles & $\begin{array}{l}\text { «Podemos se abstiene en la iniciativa del congreso para } \\
\text { liberar a los presos políticos en Venezuela» }\end{array}$ & 132 & Política \\
\hline Lunes & $\begin{array}{l}\text { «Es una vergüenza que me hayan dejado así la boca y no } \\
\text { piten ni falta» }\end{array}$ & 57 & Deportes \\
\hline Lunes & $\begin{array}{l}\text { «Otegi dará un discurso en el parlamento europeo, invitado } \\
\text { por Podemos» }\end{array}$ & 46 & Política \\
\hline Lunes & $\begin{array}{l}\text { «Un guardia civil, detenido por matar de } 3 \text { disparos a un } \\
\text { conductor» }\end{array}$ & 46 & Sucesos \\
\hline Viernes & $\begin{array}{l}\text { «Bruselas pide soluciones a España sobre el drama de los } \\
\text { desahucios» }\end{array}$ & 43 & Economía \\
\hline Lunes & $\begin{array}{l}\text { «a emoción de un niño en un concierto de Coldplay se } \\
\text { hace viral» }\end{array}$ & 42 & Varios \\
\hline Martes & $\begin{array}{l}\text { «Hoy hace } 30 \text { años se producía el accidente nuclear más } \\
\text { grave de la historia» }\end{array}$ & 39 & Sucesos \\
\hline Lunes & $\begin{array}{l}\text { «42 años de esta imagen... } 42 \text { años de la revolución de los } \\
\text { claveles» }\end{array}$ & 35 & Política \\
\hline Jueves & $\begin{array}{l}\text { «600 kilos de monedas de bronce romanas en un parque de } \\
\text { Tomares, en Sevilla» }\end{array}$ & 27 & Varios \\
\hline Viernes & $\begin{array}{l}\text { «Prince ocultaba que tenía Sida y que su estado era muy } \\
\text { grave, según medios» }\end{array}$ & 27 & Cultura \\
\hline
\end{tabular}

Fuente: elaboración propia.

\section{DisCUSIÓN DE LOS RESULTADOS Y CONCLUSIONES}

A pesar de que Telecinco es el canal de televisión que acumulaba el mayor número de comentarios sobre sus programas en las redes sociales, cuando nos centramos en la información, los dos espacios de Atresmedia, Antena 3 Noticias y La Sexta Noticias, son los preferidos por los usuarios de Twitter para consumir noticias a través de la red social. Ambos programas juntos suman más de la mitad de las noticias publicadas en Twitter, dato que contrasta con los arrojados por la audiencia convencional, donde Informativos Telecinco y el Telediario de La 1 son los informativos diarios que lideran la audiencia tradicional, tanto durante el prime time semanal como en la sobremesa de lunes a domingo. Este hecho pone de manifiesto una división en las preferencias de la audiencia a la hora de informarse, dependiendo de si esta prefiere hacerlo de modo tradicional o en movilidad, a través de sus smartphones.

De igual modo, el consumo de noticias de los informativos televisivos a través de Twitter también difiere del consumo tradicional en lo que a su temática se refiere. El hecho de que los usuarios puedan elegir no solo el momento y el lugar en el que quieren informarse, sino también la noticia (el contenido), hace que la audiencia deje claras sus preferencias temáticas en lo que a información se refiere, provocando que no todas las noticias ofrecidas por los canales generalistas en el canal de Twitter de sus informativos sean seguidas en la misma medida por los usuarios. Y es que, mientras las informa- 
ciones relacionadas con sucesos, política y sociedad aglutinan la mitad de las informaciones publicadas por los servicios informativos en Twitter, coincidiendo de este modo con buena parte de las noticias destacadas por esos espacios en los titulares de sus programas televisivos, son las incluidas dentro de la categoría de «varios» y de «sociedad», sobre todo, las más seguidas y retuiteadas por los usuarios de esa red social. Se trata de una tendencia que, a pesar de ser mayoritaria entre los espacios analizados, no es seguida por todos los usuarios de las páginas de Twitter de los diferentes informativos, donde, en función de cuáles son las noticias más retuiteadas, queda claro qué tipo de informaciones prefieren los seguidores, de uno u otro canal, a través de Twitter.

Así, mientras en La Sexta Noticias destaca el personalismo en las informaciones más seguidas, con la noticia del despido de Prisa del periodista Ignacio Escolar, en Telecinco las noticias más retuiteadas, a excepción de las referentes a sucesos y economía, son las que giran en torno a temas de escaso interés informativo, como las lágrimas de Amancio Ortega en la fiesta de su cumpleaños o lo que opina Albert Rivera sobre el acuerdo del Pardo, mientras que Antena 3 Noticias es el espacio con más informaciones en «varios», el Telediario cuenta con mayor número de seguidores en asuntos políticos -sin que ninguno de ellos haga referencia a la falta de acuerdo entre los partidos políticos- y deportivos, y Noticias Cuatro en temas políticos. A pesar de que las noticias políticas figuran entre las más seguidas en varios informativos, pocas veces los temas publicados en Twitter y seguidos por la audiencia están relacionados con el asunto informativo de la semana, que es la convocatoria de nuevas elecciones generales si no hay acuerdo entre las fuerzas políticas.

También destaca el hecho de que, mientras en las emisiones convencionales de los informativos analizados se repiten las mismas noticias, en el caso de las informaciones publicadas en Twitter, pocas veces coinciden las noticias más seguidas en diferentes canales. Así, por ejemplo, el Telediario, La Sexta noticias e Informativos Telecinco no coinciden en ninguna información entre las diez más seguidas en la red social. Ello es debido, sobre todo, a que mientras el Telediario busca proyectar la imagen de España a nivel deportivo y político con noticias favorables -lo que provoca que no haya ningún tuit relativo a la noticia política de la semana-, las otras dos cadenas se decantan más por aquellos temas que pueden generar controversia entre la ciudadanía.

El hecho de que la proyección informativa que los canales de televisión pueden hacer a través de Twitter no esté sujeta, al contrario que en sus emisiones convenciones, a una duración determinada, hace que no todos los días de la semana cuenten con la misma actividad en la red social. Así, viernes, sábado y domingo fueron los días con mayor número de tuits en TVE; para Informativos Telecinco, el martes y el jueves fueron las jornadas con mayor actividad en la red social; en Antena 3 Noticias, el lunes, martes y viernes; en La Sexta Noticias, el domingo, y en Noticias Cuatro, el martes.

Por último, cabe concluir que, con los resultados de este análisis, se percibe cómo cada canal de televisión prioriza noticias de distinto carácter, respondiendo a su ideología y a su estrategia mediática de una forma más clara que en la escaleta de emisión convencional, al tiempo que la audiencia hace su propia selección de las noticias que consume en Twitter en función del canal de televisión que, en un momento determinado, utilice para informarse.

\section{BIBLIOGRAFÍA}

Adelantado, E. y Martí, J. (2011). Contenidos audiovisuales y televisivos para dispositivos móviles: una aproximación al mercado español. AdComunica, 1, 99-113.

Barlovento Comunicación (2016). Informe de audiencia de abril de 2016. Recuperado de http://www.barloventocomunicacion.es/blog/129-informe-audiencias-tv-abril-2016.html (consultado el 10 de abril de 2016). 
Caldevilla Dominguez, D. (2010). Las Redes Sociales. Tipología, uso y consumo de las redes 2.0 en la sociedad digital actual. Documentación de las Ciencias de la Información, 33, 45-68.

Centro de Investigaciones Sociológicas (2016). Barómetro de abril. Recuperado de http://www.cis.es/cis/opencm/ES/1_encuestas/estudios/ver.jsp?estudio=14277 (consultado el 15 de julio de 2016).

Ditrendia (2016). Informe mobile en España y en el mundo. Recuperado de http://www.ditrendia.es/wpcontent/uploads/2016/07/Ditrendia-Informe-Mobile-en-Espa\%C3\%B1a-y-en-el-Mundo-20161.pdf (consultado el 10 de marzo de 2016).

Gómez, M., Paniagua, F. J. y Farias, P. (2015). Comportamiento de la audiencia de televisión en las redes sociales. Una aproximación al perfil y programas más comentados. Revista Latina de Comunicación Social, 70, 539-551. Recuperado de http://www.revistalatinacs.org/070/paper/1058/28es.html (consultado el 5 de mayo de 2016).

Gómez-Rubio, L. y López-Vidales, N. (2015). Del éxito en televisión a la participación en las redes sociales. El Príncipe y Galerías Velvet en Facebook. Doxa Comunicación, 20, 137-160.

IAB (2016). Estudio anual de redes sociales. Recuperado de http://www.iabspain.net/wpcontent/uploads/downloads/2016/04/IAB EstudioRedesSociales 2016 VCorta.pdf (consultado el 20 de mayo de 2016).

IAB (2015). Estudio anual de redes sociales. Recuperado de http://www.iabspain.net/wpcontent/uploads/downloads/2015/01/Estudio Anual Redes Sociales 2015.pdf (consultado el 20 de mayo de 2015).

Innovacionaudiovisual.com (24/04/2015). Antena 3 Noticias: el primer canal en incorporar Periscope en sus emisiones. Recuperado de https://innovacionaudiovisual.com/2015/04/24/antena-3noticias-el-primer-canal-en-incorporar-periscope-en-sus-emisiones/ (consultado el 17 de agosto de 2016).

Kantar Media (2016). Anuario social TV. Recuperado de http://www.kantarmedia.com/es/blog-yrecursos/data-lab/anuario-social-tv (consultado el 30 de abril de 2016).

Libertaddigital.com (2014). El 66 por ciento de los usuarios de móvil tuitea mientras ve la televisión. Recuperado de http://www.libertaddigital.com/ciencia-tecnologia/internet/2014-07-09/el-66por-ciento-de-usuarios-de-movil-tuitean-mientras-ve-la-television-1276523404/ (consultado el 25 de junio de 2016).

Lovato, A. (2015). Periodismo ubicuo. El flujo de trabajo del periodista móvil. En F. Irigaray, (Ed.), Reflexiones móviles: el periodismo en la era de la movilidad (pp. 21-31). Universidad Nacional de Rosario.

Manna, G. (2015). El oficio del periodista en tiempos de información móvil. La construcción de la noticia e importancia de la planificación. En F. Irigaray (Ed.), Reflexiones móviles: el periodismo en la era de la movilidad (pp. 100-110). Universidad Nacional de Rosario.

Marketingdirecto.com (20/03/2012). ¿Cómo influyen Facebook y Twitter en el consumo de información online? Recuperado de http://www.marketingdirecto.com/digital-general/social-mediamarketing $/ \% \mathrm{C} 2 \% \mathrm{BF}$ como-influyen-facebook-y-twitter-en-el-consumo-de-informacion-online/ (consultado el 7 de julio de 2016).

Marta-Lazo, C. y Aguilera Gonzalo, A. (2015). La audiencia social a través de Twitter en el programa La Voz. En N. Quintas-Froufe y A. González Neira (Coords.), La participación de la audiencia en la televisión: de la audiencia activa a la social (pp. 83-103). Madrid: Asociación para la Investigación de los Medios de Comunicación (AIMC). 
Moreno, G. (2015). Activismo y periodismo móvil. La experiencia de Midia Ninja en Brasil. En F. Irigaray (Ed.), Reflexiones móviles: el periodismo en la era de la movilidad (pp. 68-77). Argentina: Universidad Nacional de Rosario.

Movilonia.com (01/05/2015). La Sexta Noticias, ahora también desde WhatsApp. Recuperado de http://www.movilonia.com/noticias/la-sexta-noticias-en-whatsapp-telegram-twitter-facebook/ (consultado el 4 de julio de 2016).

Negredo, S., Vara-Miguel, A. y Amoedo, A. (2016). DigitalNewsreport.es 2016. Universidad de Navarra.

Nicolás Ojeda, M. A. (2012). Consideraciones sobre comunicación publicitaria y redes sociales: usuarios, características, estrategias y planificación. En M. A. Nicolás Ojeda y M. M. Grandío Pérez (Coords.), Estrategias de comunicación en redes sociales (pp. 13-30). Barcelona: Gedisa.

Nielsen (2015). Siete de cada diez españoles quieren total libertad para consumir vídeo en cualquier momento y lugar. Recuperado de http://www.nielsen.com/es/es/press-room/2015/siete-decada-diez-espanoles-quieren-total-libertad--para-consum.html (consultado el 26 de junio de 2016).

Noguera Vivo, J.M. (2010). Redes sociales como paradigma periodístico. Medios españoles en Facebook. Revista Latina de Comunicación Social, 65, 176-186. Recuperado de www.revistalatinacs.org/10/art/891 UCAM/13 JM Noguera.html (consultado el 30 de junio de 2016).

The Cocktail Analysis (2008). Televidente 2.0. Recuperado de http://www.slideshare.net/TCAnalysis/televidente-20-primera-oleada (consultado el 6 de abril de 2016).

Reuters Institute for the Estudy of Journalism (2015). Reuters Institute Digital News Report 2014: España. Universidad de Oxford y Universidad de Navarra.

Segado-Boj, F., Díaz-Campo J. y Soria, M. (2015). La viralidad de las noticias en Facebook. Factores determinantes. Telos, 100, 153-161.

Sequera Díaz (2013). Televisión y redes sociales: nuevo paradigma en la promoción de contenidos televisivos. Ámbitos, 22. Recuperado de: http://ambitoscomunicacion.com/2013/television-yredes-sociales-nuevo-paradigma-en-la-promocion-de-contenidos-televisivos/ (consultado el 10 de julio de 2016).

Yuste, B. (2015). Las nuevas formas de consumir información de los jóvenes. En R. Rubio, y A. Martín (Coords.), Jóvenes y generación 2020, Revista de Estudios de Juventud. Observatorio de la Juventud de España (INJUVE), pp. 179-101. Recuperado de http://www.injuve.es/sites/default/files/2015/35/publicaciones /14.\%20Las $\% 20$ nuevas $\% 20$ for ma $\% 20 \mathrm{de} \% 20$ consumir $\% 20$ informaci $\% \mathrm{C} 3 \% \mathrm{~B} 3 \mathrm{n} \% 20 \mathrm{de} \% 20 \mathrm{los} \% 20 \mathrm{j} \% \mathrm{C} 3 \% \mathrm{~B} 3$ venes.pdf (consultado el 9 de marzo de 2016).

VV. AA. (2016). La Sociedad de la Información en España 2015. Madrid: Fun. 